\title{
Algunas consideraciones sobre los temas de los cuentos tradicionales de Castilla y León
}

La difusión y la transmisión de los cuentos tradicionales del mundo hispánico son problemas de interés perenne para los que se interesan por la cultura popular española. Para proceder sobre una base relativamente firme en estudios de estos problemas sería de gran utilidad contar con datos positivos sobre las condiciones en que se encuentran los cuentos en la actualidad en las diversas regiones hispánicas. Por su importancia en el desarrollo de la cultura española, las regiones que ocupaban los antiguos reinos de Castilla y León parecen servir de punto de partida indicado para investigaciones de esta clase.

La publicación en estos últimos años de varias colecciones de cuentos tradicionales de Castilla y León, con notas comparativas - especialmente la muy interesante de Julio Camarena ${ }^{1}-$, me anima a presentar un inventario provisional de los temas de la tradición oral recogidos hasta ahora en la región observada. Los textos que utilizamos abarcan un período de casi tres cuartos de siglo, lo cual proporcionará datos no sólo sobre la conservación y difusión de los temas conocidos, sino también sobre la aparición de temas no encontrados hasta ahora.

Aunque no es completamente satisfactorio para el estudio de los cuentos tradicionales del mundo hispánico, usaré, por razones prácticas, el catálogo de Aarne-Thompson ${ }^{2}$ para referirme a los diversos tipos de cuentos. Doy en nota las abreviaturas de las otras obras utilizadas para este estudio ${ }^{3}$.

Julio Camarfina Laticirica, Cuentos tradicionales de León, 2 vols. (Madrid: Seminario Menéndez Pidal y Diputación provincial de León, 1991). Abreviatura: Camarena. León.

2 Aarne-Thompson: The Types of the Folk-Tale, a Classification and Bibligography; Antti Aarne's, Verzeichnis der Märchentypen, translated and enlarged by Stith Thompson, second revision, FFC, no. 184 (Helsinki, 1961). Abreviatura Aa-Th.

3 Abreviaturas de otras obras utilizadas:

Ampudia, CA: Aurelio de Llano Roza de Ampinia, Cuentos asturianos (Madrid, 1925).

Ampudia, FA: Aurelio de Li.Ano Roza dF: Ampitia, Del folklore asturiano (Madrid, 1922).

Boggs: Ralph S. Bocic, Index of Spanish Folktales. FFC, XXXII, no. 90 (Helsinki, 1930). [1924]).

Cabal, CTA: Constantino CABAI., Los cuentos tradicionales asturianos (Madrid: Voluntad 
Presento el inventario en dos partes. La primera trata de los temas de los cuentos de animales. La segunda trata de los temas de los cuentos maravillosos.

\section{LOS CUENTOS DE ANIMALES}

\section{A. Animales salvajes}

Aa-Th, 1, El robo de peces. Versiones (recuérdese que se trata solamente de versiones recogidas en las regiones que nos interesan, es decir, Castilla y León): Espinosa, CPE, núm. 202, El lobo desollado vivo. Espinosa, hijo, núm. 1, La raposa y el sardinero. Camarena, León, núm. 1 (Aa-Th, $1+2 \mathrm{~B}$, Cesta llena de piedras atada al rabo del lobo, +5 , Mordiendo la pata). Difusión (en todos los casos las notas se refieren solamente a la difusión del cuento en las regiones estudiadas): el cuento está muy difundido; se cuenta independientemente y también combinado con Aa-Th, núms. 2 (El lobo pesca con una cesta atada al rabo), 32 (El lobo baja en una herrada y salva a la zorra en la otra), 50 (El león enfermo) y 73 (Cegando al guarda), además de los tipos mencionados anteriormente.

Aa-Th, 2, El lobo pesca con una cesta atada al rabo. Versiones: Espinosa, hijo, núm. 4, El de las mangas y el capiruchuelo (Aa-Th, $1+2+50+5)$. Espinosa, CPE, núm. 223, La rapiega y la raposa. En Espinosa, hijo, núm. 54 se cuenta del sapo y la zorra (Aa-Th, 275, La carrera de la zorra y el sapo +2). Difusión: escasa. De mayor difusión es la variante Aa-Th, 2B (Cesta llena de piedras atada al rabo del lobo), como en Espinosa, CPE, núm. 209 (El lobo va a comer sardinas), y Camarena, León, núm. 4, La zorra Maruxina y el lobo Andrés (Aa-Th, 4, El lobo lleva a cuestas a la zorra, que finge estar enferma, + 2B). En Espinosa, CPE, núm. 211, El lobo engañado por la zorra y el león, va seguido de Aa-Th, 50 (El león enfermo).

Aa-Th, 4, El lobo lleva a cuestas a la zorra, que finge estar enferma. Versiones: Cabal, FA, p. 233. Camarena, León, núm. 5, El zorro y los

Cabal, FA: Constantino Cabal, Del folklore de Asturias (Madrid: Voluntad [1923]).

Espinosa, CPE: Aurelio M. Espinosa, Cuentos populares españoles, 3 vols. (Madrid, 1946-1947).

Espinosa, hijo: Aurelio M. Espinosa, Cuentos populares de Castilla y León, 2 vols. (Madrid: CSIC, Biblioteca de Dialectologia y Tradiciones Populares, XX, XXIII, 1987-1988).

Robe: Stanley L. Rorf, Index of Mexican Folktales (Berkeley, Los Angeles, London: University of California Press, 1973).

Thompson: Stith Tномтом. Motif-Index of Folk-Literature, revised and enlarged edition, 6 vols. (Indiana: Indiana University Press, Bloomington, 1955-1959. 
malladores; véase también Aa-Th, 2B. Difusión: parece estar poco difundido.

Aa-Th, 5, Mordiendo la pata. Versiones: Espinosa, hijo, núm. 6, La zorra y el galgo; véase también Aa-Th, 1. Se halla también en Espinosa, CPE, núm. 257, Los tres gorrinicos (Aa-Th, 124). Difusión: no parece estar muy difundido.

Aa-Th, 6, [Habla la zorra y pierde su presa]. Versiones: Espinosa, CPE, núm. 259, La zorra y el alcaraván; véase también Aa-Th, 56A. Camarena, León, núm. 6. Difusión: el tema general está muy difundido.

Aa-Th, 9, El compañero injusto. Versiones: Espinosa, hijo, núms. 8, La mariquita y la zorra, 9, La pajarilla y la zorra, 10. La zorra y la cigüeña siembran, 11. La regallarona y la raposa. Núms. 8 y 9 concluyen con la conclusión de Aa-Th, 56B (el perro finge estar muerto para matar a la zorra). Difusión: al parecer está poco difundido.

Aa-Th, 15, El robo de miel (leche, una oveja). Versiones: Espinosa, CPE, núm. 214, La raposa y el lobo. Espinosa, hijo, núm. 12, Principiéle. Camarena, León, núm. 8, La zorra, el lobo y la jarra de leche. Difusión: parece estar algo difundido.

Aa-Th, 32, El lobo baja en una berrada y salva a la zorra en la otra. Versiones: Espinosa, CPE, núm. 206, El lobo cree que la luna es queso (seguido de Aa-Th, 34). Espinosa, hijo, núm. 15, La zorra y el oso. Camarena, León, núm. 10, El queso reflejado en el pozo. Difusión: no parece estar muy difundido.

Aa-Th, 34, El lobo se echa al agua creyendo que la luna es queso. Existen múltiples variantes. Aa-Th, 34B, el lobo trata de beberse el agua de un pozo para llegar al queso (Ampudia, CA, núm. 165, El lobo Juan y la raposa María; otra versión en Espinosa, CPE, 201, El lobo, la chona y la zorra, como uno de los episodios de Aa-Th, 122A, El lobo busca el desayuno). En Espinosa, hijo, núm. 14, El lobo cae en el pozo, el lobo y la zorra se turnan sosteniéndose por una pata.

El motif Thompson, K521.3, el disfrazarse para poder evadirse, típico de Aa-Th, 36, se halla en varios cuentos: Espinosa, hijo, núm. 1, La raposa y el sardinero; Camarena, León, núm. 1, El lobo pesca con una cesta atada al rabo. En Espinosa, hijo, núm. 5, El lobo y los diablos enramados, la zorra enrama las cabras para asustar al lobo. En Camarena, León, núm. 25, La Fieitada, la Cantroxada y la Follacada, la zorra se disfraza en vano para ir de invitada a comer una untaza. Ninguno parece estar muy difundido.

Aa-Th, 37*, El zorro como pastor. Versiones: Camarena, León, núms. 11, La raposa pastora, y 12. La zorra guarda ganado. Se trata de aportaciones interesantes, sin antecedentes hispánicos. Véase el comentario de Camarena, León, p. 368.

Aa-Th, 47C, La raposa ata el cabo de una soga al cuello del lobo y el otro cabo a una vaca. Versiones: Camarena, León, núm. 13. En una 
variante, Camarena, León, núm. 15, El raposo Martín Pérez y la raposa Maria Garcia, un burro se hace el muerto para recobrar unas cornales para su amo. De poca difusión.

Aa-Th, 47D, El perro quiere matar un caballo imitando al lobo. Versión: Camarena, León, núm. 14, Meregildo (un raposín trata de imitar al lobo). De escasa difusión.

Aa-Th, 50, El león enfermo. Versiones: Ampudia, CA, núm. 174, El oso y la raposa. Espinosa, CPE, núm. 211, El lobo engañado por la zorra y el león (Aa-Th, 2+50). De escasa difusión. También raro es Aa-Th, 50B, La zorra lleva al asno a la cueva del león pero es comida por los animales. Espinosa, CPE, núm. 210, El zorro engañado por el burro y el león.

Aa-Th, 51A, La zorra rebusa servir de medianera. Versión: Ampudia, núm. 163, El león y la leona. De escasa difusión.

Aa-Th, 56A, La zorra amenaza a la urraca con derribar su árbol. Versiones: Espinosa, CPE, núm. 258, La pega y sus peguitos (termina con Aa-Th, 6). Espinosa, hijo, núm. 16, La picaciña y los picaciños (termina con Aa-Th, 6). Camarena, León, núm. 16, Serra, meu rabo. Al parecer va desapareciendo de la corriente oral.

Aa-Th, 56B, Th K911, Fingiendo estar muerto para apresar al enemigo + Aa-Th, 568*, La zorra bebe y rie. Versiones: Espinosa, hijo, núms. 8, La mariquita y la zorra (episodio final), y 9, La pajarilla y la zorra (episodio final). De difusión limitada.

Aa-Th, 59, La zorra y los agraces. Versiones: Espinosa, CPE, núm. 226, La zorra y las uvas verdes. Espinosa, hijo, núm. 25, La zorra y las uvas. Camarena, León, núm. 18. La zorra y las ciruelas verdes. Difusión: aunque el tipo no está muy difundido, hay una serie de cuentos en que la zorra queda frustrada en circunstancias parecidas: Camarena, León, núm. 17, La raposa y los folgueiros (la zorra corre en vano creyendo que los folgueiros son uvas); núm. 22, La zorra en el ciruelo (un rayo le rompe el rabo); núm. 23, La zorra que estaba a las cerezas (cae un relámpago; "no alumbres tanto"); núm. 24, La zorra y el rayo (volviendo de comer ciruelas, le pega un rayo en el rabo).

Aa-Th, 60, La zorra y la cigüeña se invitan. Versiones: Espinosa, hijo, núm. 21, La zorra y la cigüeña (termina con Aa-Th, 225, La cigüeña enseña a la zorra a volar). Camarena, León, núm. 19, La zorra y la cigüeña se invitan. De poca difusión.

Variante de Aa-Th, 61A, El zorro como confesor. Camarena, León, núm. 20, La zorra y las plumas del gallo (precedido del comienzo de Aa-Th, 62, Paz entre los animales).

Aa-Th, 62, Paz entre los animales. Versiones: Ampudia, CA, núm. 184, El gallo y la raposa. Camarena, León, núm. 21, Las propiedades de la raposa (variante). De poca difusión.

Aa-Th, 67, El zorro dentro del crecido rio pretende estar nadando bacia un pueblo distante. Versión: Camarena, León, núm. 9, Em principiallo, 
Amediallo, Acaballo (final de Aa-Th, 15, El robo de miel simulando el papel de padrino). Cabal, $F A$, p. 176. Sobre su escasa difusión, véase la nota de Camarena, León, pp. 366-367.

Aa-Th, 69**, Escape pidiendo un último beso. Versión: Espinosa, CPE, núm. 265, La zorra y el erizo.

Aa-Th, 73, Cegando el guarda. Versión, Espinosa, hijo, núm. 2, El aceitero $y$ la zorra (el final de Aa-Th, 1).

Aa-Th, 75*, El lobo espera en vano que la niñera le eche los niños. Camarena, León, núm. 44, De pico mata el arriero al borrico, recoge una variante con puntos de contacto con Aa-Th, 154*, Regalo al lobo o a la zorra.

Aa-Th, 77, El ciervo admira su cornamenta. Variante: Camarena, León, núm. 26, La zorra admira su rabo. Poco difundido.

Aa-Th, $77^{*}$, El lobo confiesa sus pecados a Dios. Variantes: Camarena, León, núm. 69, El lobo cumple la penitencia (.justo, justico, juna libra la burra y media el borrico!n). Ampudia, CA, núm. 73, Lo justo, justito (se cuenta de un ladrón).

Aa-Th, 78, Un animal permite que le aten a otro para salvarse. Versión: Espinosa, hijo, núm. 28, El asno y el león (Aa-Th, 103C*, Un asno viejo echado al campo por su amo se encuentra con un oso o león, seguido de Aa-Th, 118, El león asustado por el caballo o asno).

$\mathrm{Aa}-\mathrm{Th}, 80 \mathrm{~A}^{*}$, ¿Quién se lleva la colmena? Versiones: Espinosa, CPE, núm. 268, El oso, el lobo y la zorra. Espinosa, hijo, núm. 26, El oso, el lobo y la zorra. De escasa difusión.

B. Los animales salvajes y domésticos

Aa-Th, 100, El lobo como buésped del perro canta. Versión: Espinosa, $C P E$, núm. 201 (Aa-Th, 34+122A, El Lobo busca el desayuno + 100). De poca difusión.

Aa-Th, 103C*, Un asno viejo echado al campo se encuentra con un oso o león. Versiones: Espinosa, CPE, núm. 249. El burro, el oso, el lobo y la zorra (termina con Aa-Th, 78, Un animal permite que le aten a otro para salvarse). Espinosa, hijo, núm. 28, El asno y el león (termina con Aa-Th, 118, El león asustado por el caballo o asno). No parece estar muy difundido.

Aa-Th, 118, El león asustado por el caballo o asno. Versiones: Espinosa, CPE, núm. 249, El burro, el oso, el lobo y la zorra (Aa-Th, 103C*, Un asno viejo echado al campo se encuentra con un oso o león +78 , un animal permite que le aten a otro para salvarse). Espinosa, hijo, núm. 28, El asno $y$ el león (Aa-Th, 103C +118$)$.

Aa-Th, 120, El que primero ve la salida del sol. Versiones: Espinosa, hijo, núm. 29, El lobo y la zorra. Camarena, León, núm. 62, A raposa y o sapo (Aa-Th, 275, La carrera del zorro y el cangrejo [sapol +120). 
Aa-Th, 121, Los lobos se ponen uno encima del otro; el de abajo buye. Versión: Espinosa, CPE, núm. 255 (Aa-Th, 130).

Aa-Th, 121B*, El lobo persigue a las ovejas por la ventana. Variante: Camarena, León, 28, La cabra intenta ganarse al lobo.

Aa-Th, 122A, El lobo busca su desayuno. Versiones: Ampudia, CA, núm. 159, Las aventuras de un lobo. Espinosa, CPE, núm. 199, Buen día de vianda para el lobo. Espinosa, hijo, núm. 30. El lobo madrugador. Camarena, León, núm. 29, La zorra bautiza gochos (termina con Aa-Th, 135A*, El zorro tropieza con un violín). Muy difundido, así como sus múltiples y variadas variantes, como las siguientes.

Aa-Th, 122D, La victima se ofrece a traer mejor presa. Versión: Espinosa, hijo, núm. 7, El lobo quemado vivo.

Aa-Th, 122F, "Espere hasta que me engorde". Versiones: Espinosa, CPE, núm. 221, El gato Laureano. Ampudia, CA, núm. 162, La zorra y el gato. Fspinosa, hijo, núm. 44, La viejecilla y los lobos. Camarena, León, núm. 30, La raposa y el gato Miguel.

Aa-Th, 122H, "Espere basta que me seque»Versión: Espinosa, hijo, núm. 40, El ratón y el gato.

Aa-Th, 122Z, Otras astucias para evitar ser apresados. Versiones: Camarena, León, núm. 32, La oveja glotona; núm. 33, O lobo da una carra en vano. Fspinosa, hijo, núm. 39, El ratón y el gato (jugando a la pelota, el ratón no se aleja de su madriguera).

Aa-Th, 123, El lobo y los cabritos. Versiones: Espinosa, hijo, núm. 32, La cabra y sus chivitos. Camarena, León, núm. 34, El lobo y los cabritos.

Aa-Th, 126A*, Los lobos asustados. Versión: Camarena, León, núm. 36, El gato y' el carnero espantan a los lobos.

Aa-Th, 127A*, El lobo trata de persuadir a la cabra a bajar de una peña. Versión: Ampudia, CA, núm. 167, El lobo y la cabra. Versiones de palabras forjadas repetidas: Ampudia, $C A$, núm. 197, Cabra cabratis. Fspinosa, CPE, núm. 216, Cabrín cabrates y lobin lobates. En tres versionés de Fspinosa, hijo, núms. 35, 36 y 37, la cabra baja y la come el lobo. Camarena, León, núm. 296, Cabrín cabrate.

Aa-Th, 1278*, Una cabra entra en un buerto para comer $y$ no puede salir. Una zorra critica su poco sentido. Ampudia, CA, núm. 166, La cabra l' la raposa.

Aa-Th, 129A*, lina oveja está lamiendo a un bijo suyo. El lobo: ¡Cuánto es la mala conducta! Si fuera yo, ya decían que lo estaba comiendo! Versiones: Ampudia, CA, núm. 169, El lobo y la oveja. Camarena, León, núm. 35, El lobo se lamenta de su mala fama.

Aa-Th, 130, Los animales viajeros se alojan en una casa de ladrones. Versiones: Espinosa, CPE, núm. 256, Los músicos de Móstoles. Espinosa, hijo, núm. 38, Los animales inútiles. Camarena, León, núm. 37, Los animales muisicos. 
Aa-Th, 135A*, El zorro tropieza con un violin. Versiones: Ampudia, $C A$, núm. 168, La zorra y los perros. Espinosa, CPE, núm. 224, El galgo y la zorra (se encuentra con un ciego tocando). Espinosa, hijo, núm. 24, Catalina, la zorra (Aa-Th, núm. 62, Paz entre los animales, $+135 \mathrm{~A}^{*}+161$, El labrador delata a la zorra apuntando.

C. El hombre y los animales salvajes y domésticos

Aa-Th, 153, La castración del oso y la búsqueda de ungüento (sólo Thompson, K1012.1, Fortaleciéndole al inocentón por castración). Versión: Camarena, León, núm. 39, El lobo se hace castrar.

Aa-Th, 154, Comida de oso. Versiones: Ampudia, CA, núm. 170, El labrador y el oso. Espinosa, CPE, núm. 222, Xuan, el oso y la raposa. Camarena, León, núm. 40, Mal oso te albarde.

Aa-Th, 155, La serpiente desagradecida. Versiones: Ampudia, CA, núm. 171, El cuélebre y el pastor. Espinosa, CPE, núm. 264, In bien con un mal se paga. Espinosa, hijo, núm. 41, El hombre y la serpiente. Parece estar poco difundido actualmente.

Aa-Th, 156, La espina sacada de la pata del león. Variante: Camarena, León, núm. 38, O médico y o lobo.

Aa-Th, 157, Aprendiendo a temer al hombre. Versiones: Ampudia, $C A$. núm. 170, El oso y el herrero. Espinosa, CPE, núm. 261, El leớn y el hombre. Espinosa, hijo, El león y el bombre. Camarena, León, núm. 45, il joven león busca al hombre.

Robe, $157^{*} \mathrm{E}$, El asno recobra los arreos. Versiones: Camarena, León, núm. 42, El labradore y el oso (Aa-Th, 154, Comida de oso, + Robe, $157^{*} \mathrm{E}+\mathrm{Aa}-\mathrm{Th}, 47 \mathrm{C}$, El zorro ata un cabo de la soga al cuello del lobo $y$ el otro a los cuernos de una vaca); núm. 43, El asno recohra los arreos (los mismos tres temas).

Aa-Th, 159A, Los animales se calientan a la lumbre del carbonero. Versiones: Camarena, León, núm. 48, La vieja del Cabezo; núm. 49, El tío Amin. Son muy interesantes por representar tipos poco difundidos.

Aa-Th, 161, El labrador delata a la zorra apuntando. Versiones: Ampudia, CA, núm. 161, El labrador y la zorra. Espinosa, hijo, núm. 24. Catalina, la zorra (Aa-Th, 62, Paz entre los animales $+135 \mathrm{~A}^{*}$, bl zorro tropieza con un violin +161).

Aa-Th, 165B*, El mayor castigo del lobo: casarlo. Versión: ampudia, CA, núm. 192, El castigo del lobo.

Boggs, *166, El lobo disfrazado de pastor engaña a una vieja. Versiones: Ampudia, CA, núm. 160, El lobo y la vieja (Aa-Th, 127A*, El lobo persuade a una cabra a bajar de una peña + Boggs "166). Camarena, León, núm. 50, El lobo disfrazado de pastor engaña a la vieja. 
Aa-Th, 168, El músico en la trampa para lobos. Variantes: Camarena, León, núms. 51, El músico espanta a los lobos; 52, El tamboritero al que le salió el lobo; 53, El gaitero y el lobo.

Aa-Th, 175, El muñeco de brea y el conejo. Cf. Aa-Th, 650.

Aa-Th, 201, El perro flaco prefiere la libertad. Variante: Espinosa, hijo, núm. 45, El consejo de los perros (un perro viejo aconseja no cambiar la situación presente).

Aa-Th, 222, Guerra entre pájaros y cuadrúpedos. Versiones: Espinosa, CPE, núm. 246, El león, el grillo y el zorro (contiene Aa-Th, 34, El lobo se echa al agua creyendo que la luna es queso). Espinosa, hijo, núm. 50, El grillo y el león. Camarena, León, núm. 54, La guerra entre los animales de pelo y los de pluma.

Aa-Th, 225, La cigüeña enseña a la zorra a volar. Versiones: Ampudia, $C A$, núm. 172, El alcarabán y la zorra. Espinosa, CPE, núm. 218, La zorra y la cigüeña. Espinosa, hijo, núm. 21, La zorra y la cigüeña (Aa-Th, núm. 60, La zorra y la cigüeña se invitan +225). Camarena, León, núm. 56, La cigüeña y la raposa (comienza con Aa-Th, 60, La zorra y la cigüeña se invitan).

Aa-Th, 229B*, Un águila avisa al pastor de que el lobo está comiendo ovejas. Versiones: Cabal, FA, p. 236. Camarena, León, núm. 58, El águila avisa a los pastores; núm. 59, La pega delata al lobo. (Véase el comentario de Camarena, León, p. 394).

Aa-Th, 232, El gallo de bosque y los pájaros migratorios. Variante: Espinosa, hijo, núm. 51, El pecu y el alcotán (el alcotán es más fuerte que el pecu, que pasa el invierno en tierras cálidas).

Aa-Th, 243A, Los gallos que cantan del adulterio de su ama. Versión: Espinosa, CPE, núm. 263, Oír, ver y callar (El gallo discreto se salva).

Aa-Th, 246, El cazador se dispone a disparar la flecha. Variante: Camarena, León, núm. 60, La enseñanza del gorrión.

Tipo 260 (sugerencia del autor): Camarena, León, 61, Los bichos piden dones (El hombre pide "cencia y mañan; la zorra comenta, - Cuidao con los de dos patas).

\section{Otros animales y objetos}

Aa-Th, 275, La carrera de la zorra y el sapo. Versiones: Ampudia, CA, núm. 175, La raposa y el sapo. Espinosa, CPE, núm. 230, El sapo y la zorra. Espinosa, hijo, núm. 52, El sapo y la zorra; núm. 54, El sapo y la zorra (seguida de Aa-Th, 2, El lobo pesca con una cesta atada al rabo). Camarena, León, núm. 63, La carrera entre el sapo y la zorra.

Boggs, 275*A, La carrera entre la zorra, ratón o liebre y el sapo o erizo (uno o más de la misma especie colocados a lo largo del trayecto). Versiones: Ampudia, CA, núm. 173, El sapo y el ratón. Espinosa, CPE, 
núm. 227, El erizo y la liebre. Espinosa, hijo, núm. 55, El erizo y la liebre. Espinosa, hijo, núm. 55, El erizo y la liebre.

Aa-Th, 275B*, La carrera entre el lobo y la abeja. Versión: Espinosa, $C P E$, núm. 232, El lobo y las abejas.

Aa-Th, 285B, Una nuez (pera) al caer despierta a un hombre cuando se le acerca una serpiente (un toro). Versiones: Ampudia, CA, núm. 137, Larga $y$ angosta. Cabal, $F A$, p. 236. Espinosa, hijo, núm. 57, Pinguilis, pinguilis.

Aa-Th, 285C, Labrador da de comer a serpiente para que no le coma el ganado; le da piedras calientes. Versiones: Ampudia, FA, p. 49.

Boggs, *287, Cambio del rabo del sapo por los ojos del topo. Versiones: Cabal, $F A$, p. 169. Espinosa, CPE, núm. 233, El sapo y la rana (comienzo de Aa-Th, 288A*, "jPero de buen mozo! $)$.

Aa-Th, 288A*, iPero de buen mozo! Así consuela el sapo a su mujer al ser aplastado por la rueda de un carro. Versiones: Espinosa, $C P E$, núm. 233, El sapo y la rana (precedido de Boggs, *287, Cambio del rabo del sapo por los ojos del topo). Espinosa, hijo, núm. 58, El sapo y la rana. Camarena, León, núm. 64, O sapo y a rana; núm. 65, La rana y el sapo aplastado.

Boggs, ${ }^{*} 288 \mathrm{~B}$. Semejante al tipo anterior, pero al tratar de atravesar un arroyo de un salto cae en medio de él. Versiones: Espinosa, $C P E$, núm. 235, [El escuerzo y la rana); núm. 236, IEl sapo y la sapal. Espinosa, hijo, núm. 59, El sapo.

Aa-Th, 288B*, Las prisas del sapo. Versiones: Espinosa, CPE, núms. 238, 240-242, El sapo; núm. 245, El escarabajo. Espinosa, hijo, núm. 59, El sapo (cf. Boggs, *288B); núm. 60, El sapo. Camarena, León, núm. 66, Las prisas nunca fueron buenas.

Boggs, *290, Un pastor cuida de una culebra. Al llamarla después de una larga ausencia, la culebra le ahoga. Versión: Ampudia, $C A$, núm. 50, La culebra $y$ el pastor.

Aa-Th, 294, Los meses y las estaciones. Ampudia, CA, núm. 199, Las cuentas de la vieja; núm. 187, El bombre y el paxarín. Camarena, León, núm. 67, El pastor y marzo; núm. 68, El pastor y marzo.

Cuentos sin catalogar; tal vez puedan catalogarse como variantes de Aa-Th, 298, La contienda del viento y el sol. Camarena, León, núm. 70, La niebla y la vergüenza; núm. 72, Diálogo entre la leche y el vino.

\section{LOS CUENTOS MARAVILLOSOS}

A. Los adversarios sobrenaturales

Aa-Th, 300, El dragón devastador. Versiones: Espinosa, CPE, núm. 139, El Castillo de Irás y No Volverás (precedida de elementos de Aa-Th, 303, 
Los gemelos). Espinosa, hijo, núm. 61, La joven y la serpiente. Camarena, León, núm. 73, La serpiente de siete cabezas.

Aa-Th, 301B, El bijo del oso y sus compañeros. Versiones: Espinosa, $C P E$, núm. 133, Juanito el Oso (para uno de los episodios, cf. Aa-Th, 326A*, Ánima salvada del tormento); núm. 134. Espinosa, hijo, núm. 62, Juanillo el Oso, y dos versiones más. Camarena, León, núm. 74, Juanillo el Oso; núm. 75, Juan de la Burra. Es uno de los cuentos más difundidos.

Aa-Th, 302, El alma del ogro en un buevo. Versiones: Ampudia, CA, núm. 14, El pescador y la Serena (comienza como Aa-Th, 303, Los gemelos). Espinosa, CPE, núm. 144, La loba negra. Espinosa, hijo, núm. 65, Los maridos animales y el castillo encantado. Camarena, León, núm. 76, Las Peñas del Nuncio (comienza con Aa-Th, 425P, Esposa encantada perdida y ballada).

Aa-1h, 303, Los gemelos. Versiones: Ampudia, CA, núm. 14, El pescador y la Serena (comienza como Aa-Th, 302, El alma del ogro en un buevo). Espinosa, CPE, núm. 139, El Castillo de Irás y No Volverás (con elementos de Aa-Th, 300, El dragón devastador). Espinosa, hijo, núm. 68, El Castillo de Irás y No Volverás. Camarena, León, núm. 77, El pez y el pescador.

Aa-Th, 307 [El principe] en la mortaja. Variante: Camarena, León, núm. 331, El principe con uñas y garras.

Aa-Th, 311, La habitación probibida. Versiones: Cabal, CTA, p. 25. Camarena, León, núm. 79, ¡Oreja aqui, oreja en la mesa!

Aa-Th, 311B*, El zurrón cantarín. Versiones: Ampudia, CA, núm. 47, Por no andar en justicia. Cabal, CTA, p. 55. Espinosa, CPE, núm. 41, El zurrón que cantaba. Camarena, León, núm. 80, O bome do zurrón.

Aa-Th, 312C, La novia del ladrón es rescatada. Versiones: Cabal, CTA, 15-19 (parte final). Espinosa, CPE, núm. 101, La niña sin brazos (en una versión de Aa-Th, 706, La niña sin brazos). Espinosa, hijo, núm. 91, El diablo de novio, y dos versiones más. Camarena, León, núm. 81 , La novia del ladrón (precedida de Aa-Th, 956B, La muchacha lista, sola en casa, se libra de los ladrones).

Aa-Th, 313A, La chica ayuda a la fuga del béroe. Versiones: Espinosa, CPE, núm. 124, Marisoles. Espinosa, hijo, núm. 72, Blancaflor, núm. 73, La bija del demonio. Camarena, León, núm. 84, Pedro y el diablo (termina con Thompson D610, La contienda de transformaciones, la conclusión típica de Aa-Th, 325, El mago y su alumno).

Aa-Th, 313C, La chica ayuda a la fuga del béroe + La novia olvidada. Versiones: Ampudia, CA, núm. 24, Don Pedro y el diablo. Espinosa, CPE, núm. 125, El Castillo de las Siete Naranjas. Espinosa, hijo, núm. 70, Blancaflor, la bija del demonio, y dos versiones más. Camarena, León, núm. 82, Ay del Sol, 83, Blancaflor.

Aa-Th, 325, El mago y su alumno. Versiones: Ampudia, CA, núm. 10, Periquín; núm. 11, El maestro encantador. Camarena, León, núm. 85; $O$ rey que estudiaba mágica; núm. 86, Pillín. Parece estar poco difundido. 
Aa-Th, 326, El joven que queria saber lo que es el miedo. Versiones: Espinosa, CPE, núm. 136, Juan sin Miedo; núm. 138, Periquito sin Miedo. Espinosa, hijo, núm. 77, Juan el sin miedo (con Thompson K74, El muñeco de brea, típico de Aa-Th, 175); núm. 78, Juan el sin miedo (con Thompson, $\mathrm{K} 741$, El muñeco de brea).

Aa-Th, 326A*, Ánima salvada del tormento. Versiones: Ampudia, CA, núm. 5, Las tres prendas de Pedro (episodio inicial de Aa-Th, 566, Los tres objetos mágicos y las frutas maravillosas); núm. 113, Juanillo el Oso. Espinosa, CPE, núm. 133. Juanito el Oso (final de Aa-Th, 301B). Camarena, León, núm. 89, Cuento de Chamorro (seguida de Aa-Th, 330B, El diablo en la mocbila).

Aa-Th, 327A, La casita de caramelo. Versión: Camarena, León, núm. 87, La casita de caramelo.

Aa-Th, 327B, El muchacho y el gigante. Versiones: Ampudia, CA, núm. 43, El mocoso. Espinosa, hijo, núm. 81, El Número Once. Camarena, León, Los tres hermanitos y el gigante (combinado con Aa-Th, 328, El muchacho roba el tesoro del gigante.

Aa-Th, 327C, El gigante (bruja, diablo) lleva al béroe a casa en un saco. Versión: Espinosa, hijo, núm.79, Periquín y el gigante.

Aa-Th, 328, El muchacho roba el tesoro del gigante. Versiones: Ampudia, CA, núm. 43, El mocoso (combinado con Aa-Th, 327B, El muchacho y el gigante). Espinosa, hijo, núm. 81, El Número Once (combinado con Aa-Th, 327B). Camarena, León, núm. 88, Los tres bermanitos $y$ el gigante (combinado con Aa-Th, 327B).

Aa-Th, 329, Escondiéndose del diablo (de la princesa). Versión: Camarena, León, núm. 105, Pedrito (combinado con Aa-Th, 873, El rey descubre a su bijo desconocido, y 531, Los consejeros insidiosos).

Aa-Th, 330A, El berrero aventaja al diablo. Versiones: Espinosa, hijo, núm. 82, El berrero y el demonio; núm. 83, El berrero Nájar.

Aa-Th, 330B, El diablo en la mochila. Versiones: Ampudia, CA, núm. 119, San Pedro y el herrero (con Aa-Th, 785, ¿Quién se comió la asadura?). Espinosa, CPE, núm. 168, Juan Soldao (con Aa-Th, 785, ¿Quién se comió la asadura?, y 753A, Resurrección infructuosa); núm. 169, Juan Soldao (con Aa-Th, 785, ¿quién se comió la asadura?, y 753A, Resurrección infructuosa). Camarena, León, núm. 89, Cuento de Chamorro (con Aa-Th, 326A, Ánima salvada del tormento); núm. 127, [Imitando milagros] (AaTh, 753A, Resurrección infructuosa).

Aa-Th, 330D, La tía Miseria. Versiones: Ampudia, CA, núm. 46, La tía Miseria. Espinosa, hijo, núm. 85, El peral de la tía Miseria.

Aa-Th, 330*, Entrada al cielo con engaños. Versión: Camarena, León, núm. 90, Los de caballería entran al cielo.

Aa-Th, 332, La muerte de padrino. Versiones: Ampudia, CA, núm. 20, El médico y la muerte (incompleto). Espinosa, hijo, núm. 86, La Muerte de madrina (cf. Aa-Th, 1199, El padrenuestro); núm. 87, La Muerte 
madrina (una antorcha); núm. 88, La Muerte madrina (una vela); núm. 89, El médico y la Muerte (el padrenuestro); núm. 90, Juan Holgado y la Muerte ("cuando te se desconchara la casa").

Aa-Th, 333, El glotón. Versión: Espinosa, CPE, núm. 333, El Tragaldabas.

Aa-Th, 361, Piel de Oso. Versión: Camarena, León, núm. 91, El criado del demonio.

Aa-Th, 366, La reclamación del muerto. Versiones: Espinosa, hijo, núm. 94. La asadura del muerto; núms. 95, 96, La asadura del padre; núm. 97, La asadura de la madre; núm. 98, La asadura del muerto; núm. 99, María, ia, ia; núm. 100, La asadura frita o cruda; núm. 101, La asadura del difunto; núm. 102, María Dura (empleada en el juego del escondite); núm. 103, La asadura del marido.

B. Esposos y otros parientes sobrenaturales

Aa-Th, 402, El ratón (gata, mona) de novia. Versiones: Ampudia, CA, núm. 8, La rana y la culebrina. Espinosa, hijo, núm. 105, La mona encantada.

Aa-Th, 403A, [La novia trocada y su hermano]. Versión: Camarena, León, núm. 332, A criada mala zorra.

Aa-Th, 408, Las tres naranjas. Versiones: Ampudia, $C A$, núm. 3, Las tres naranjas del amor (dos versiones). Espinosa, CPE, núm. 114, El palacio del Jarancón (precedida de Aa-Th, 451*, La bermana como misteriosa ama de casa). Espinosa, hijo, núm. 106, Las tres naranjitas del amor, núms. 107, 109, Las tres naranjas; núm. 108, Los tres capullitos; núm. 110, La reina y la mora. Camarena, León, núm. 92, Las tres naranjitas del mar, núm. 90, $A$ Tórtola.

Aa-Th, 409, La muchacha en forma de lobo. Versión: Camarena, León, núm. 94, La muchacha lobo (véase el comentario de Camarena, León, p. 414).

Aa-Th, 410, La bella durmiente. Versión: Camarena, León, núm. 95, La bella durmiente (véase el comentario de Camarena, León, pp. 415-416).

Aa-Th, 425A, El monstruo como esposo. Versiones: Ampudia, CA, núm. 1, El león y Angelina. Espinosa, CPE, núm. 128, El Castillo de Oropé. Camarena, León, núm. 96, Las hijas del sastre (precedida de Aa-Th, 433B, El príncipe serpiente mata a las novias ariscas); núm. 334, El rey Lagarto (precedida de Aa-Th, 433B, El principe serpiente mata a las novias ariscas.

Aa-Th, 425C, La belleza y la bestia. Versiones: Cabal, CTA, p. 66. Espinosa, CPE, núm. 131, La fiera del rosal. Espinosa, hijo, núm. 111, La fiera del jardín; núm. 112, La mano negra. Camarena, León, núm. 97, El Culebrón. 
Aa-Th, 425E, Esposo encantado canta nana. Versión: Camarena, León, núm. 333, El encanto de la peña (hay que quitarle un collar).

A-Th, 425P, Esposa encantada perdida y hallada. Versiones: Ampudia, CA, núm. 2, La mano negra (seguida de Aa-Th, 302, El alma del ogro en un huevo). Espinosa, hijo, núm. 66, Los animales agradecidos (seguida de Aa-Th, 302, El alma del ogro en un huevo). Camarena, León, núm. 76, Las peñas del nuncio (seguida de Aa-Th, 302).

Aa-Th, 433B, El principe serpiente mata a las novias ariscas. Versiones: Espinosa, CPE, núm. 130, El lagarto de las siete camisas. Camarena, León, núm. 96, Las hijas del sastre (seguida de Aa-Th, 425A, El monstruo como esposo); núm. 334, El rey lagarto (seguida de Aa-Th, 425A, El monstruo como esposo).

Aa-Th, 437, La novia suplantada. Versión: Espinosa, hijo, núm. 114, El rey durmiente.

Aa-Th, 440, El comerciante Sapo. Versiones: Espinosa, CPE, núm. 132, El príncipe rana. Espinosa, hijo, núm. 113, El principe encantao.

Boggs, *449, La princesa encantada desencanta al héroe. Versión: Espinosa, CPE, núm. 144, La loba negra.

Aa-Th, 451, La joven que busca a sus hermanos cuervos. Versiones: Espinosa, CPE, núm. 148, Los siete cuervos (muy alterada). Espinosa, hijo, núm. 115, Los siete cuervos.

Aa-Th, 451*, La hermana como misteriosa ama de casa. Versiones: Ampudia, CA, núm. 188, La moza y el cuervo (termina como Aa-Th, 709, Blancanieves). Espinosa, CPE, núm. 114, El palacio del Jarancón (seguida de Aa-Th, 452B*, Los hermanos bueves). Espinosa, hijo, núm. 80, Los dos toritos (seguida de Aa-Th, 452B, Los (hermanos bueyes], y la conclusión de Aa-Th, 408, Las tres naranjas). Camarena, León, núm. 98, (Los hermanos toros] (seguida de Aa-Th, 452B, [Los hermanos] bueves).

Aa-Th, 452B*, Los hermanos bueyes. Véase Aa-Th, 451*, La hermana como misteriosa ama de casa, y el comentario de Camarena, León, pp. 418-419.

\section{Tareas y ayudantes sobrenaturales}

Aa-Th, 461, Tres pelos de la barba del diablo. Versiones: Ampudia, $C A$, núm. 15, El sino de un joven. Espinosa, hijo. núm. 116, Los tres pelos del diablo.

Aa-Th, 471, El puente hacia el otro mundo. Versiones: Espinosa, CPE, núm. 87, Condenados en vida (variante). Camarena, León, núm. 99, Las tres rosas; núm. 100, Conto dos figos (variante).

Aa-Th, 480, La bilandera de la fuente. Versiones: Ampudia, CA, núm. 31, Casilda y Jimena (seguida de Aa-Th, 510A, Cenicienta [tres versiones]; núm. 32, Milimilina (seguida de Aa-Th, 510A, Cenicienta). 
Aa-Th, 500, El nombre del ayudante. Versiones: Espinosa, CPE, núm. 117, El nombre del diablo. Camarena, León, núm. 101, [El nombre del ayudante].

Aa-Th, 501, Las tres ancianas ayudantes. Versión: Camarena, León, núm. 102, Las tres bilanderas.

Aa-Th, 510A, Cenicienta. Versiones: Ampudia, núm. 31, Casilda $y$ Jimena (tres versiones) (precedida de Aa-Th, 480, La bilandera de la fuente); núm. 32, Milimilina (precedida de Aa-Th, 480). Espinosa, hijo, núm. 119, La fregona. Camarena, León, núm. 103, La Cenicienta. Aa-Th, 510B. Traje de oro, plata y estrellas. Versiones: Ampudia, CA, núm. 32, Milimilina (precedida de Aa-Th, 480, La bilandera de la fuente). Espinosa, $C P E$, núm. 109, Los tres trajes. Espinosa, hijo, núm. 123, Como la sal en el agua (Aa-Th, 923, Amor como la sal, con elementos de Aa-Th, 510B; núm. 124, Como a la sal en el agua.

Aa-Th, 511, Uno ojo, dos ojos, tres ojos. Variante: Espinosa, CPE, núm. 154, Las tres avellanas.

Aa-Th, 513A, Seis van por todo el mundo. Versiones: Ampudia, CA, núm. 134, El pandero de piel de piojo (combinado con Aa-Th, 621, La piel de piojo). Espinosa, hijo, núm. 125, La Fuente de la Teja. Camarena, León, núm. 104 [Los compañeros superdotados]; 112, La gorra de piel de piojo (precedida de Aa-Th, 621, La piel de piojo).

Aa-Th, 531, [Los consejeros insidiosos]. Versión: Camarena, León, núm. 105, Pedrito (combinado con Aa-Th, 873, El rey descubre a su bijo desconocido, y Aa-Th, 329, Escondiéndose del Diablo (de la princesa).

Aa-Th, 533*, La culebra ayudante. Versiones: Ampudia, CA, núm. 9, La niña y la culebrina. Camarena, León, núm. 106, La culebrita.

Aa-Th, 545B, El gato con botas. Versiones: Cabal, CTA, pp. 77-78. Camarena, León, núm. 107 [El gato con botas].

Aa-Th, 551, Los bijos buscan un remedio maravilloso para su padre. Versión: Espinosa, CPE, núm. 143, Las tres maravillas del mundo.

\section{Objetos mágicos}

Aa-Th, 560, El anillo mágico. Versiones: Espinosa, CPE, núm. 147, El anillo de la princesa (comienza con episodios del tonto al cuidado de la llueca, etc., Boggs, núm. *1693). Espinosa, hijo, núm. 126, La cajita mágica. Camarena, León, núm. 108, [El anillo mágico].

Aa-Th, 563, La mesa, el asno y el palo. Versiones: Espinosa, hijo, núm. 127, El burro, la mesita y el palo. Camarena, León, núm. 109, [La mesa, el asno y el palo].

Aa-Th, 566, Los tres objetos mágicos y las frutas maravillosas. Versiones: Ampudia, CA, núm. 5, Las tres prendas de Pedro (comienza con Aa-Th, 326A*, Anima salvada del tormento). Espinosa, CPE, núm. 149, El tonto lagañoso, magañoso. 
Aa-Th, 569, El zurrón, el sombrero y el cuerno. Variante: Espinosa, hijo, La pata de camero (un pobre se queda con un anillo, una cachava y un vaso mágicos).

Aa-Th, 570, La manada de conejos. Versiones: Ampudia, CA, núm. 4, El saco de verdades; núm. 132, Los tres acertijos (precedida de Aa-Th, 851, La princesa no acierta el acertijo). Espinosa, CPE, núm. 12, Juan Soldao y la Princesa (precedida de Aa-Th, núm. 851A, El pretendiente tiene que acertar un acertijo). Espinosa, hijo, núm. 130, El Saco de embustres (precedida de Aa-Th, 610, Las frutas curativas). Camarena, León, núm. 110, Cuento de los conejos.

Aa-Th, 571C, La muñeca que muerde. Versión: Espinosa, hijo, núm. 128, La muñeca de las onzas.

Boggs, *572, Haciendo reir a la princesa. Espinosa, CPE, núm. 178, La princesa que nunca se reía (seguida de Aa-Th, 570, La manada de conejos, y Aa-Th, 850, II, A quién se vuelve durante la nocbe).

Aa-Th, 590, El príncipe y los brazales. Variante: Espinosa, hijo, núm. 75, Los tres leones.

aa-Th, 594**, La flauta mágica que bace a todos bailar. Versión: Espinosa, CPE, núm. 153, La gaita que bacia a todos bailar. Variante: Ampudia, CA, núm. 34, El rapaz y la xiblata.

\section{E. Remedios mágicos}

Aa-Th, 610, Las frutas curativas. Versión: Espinosa, hijo, núm. 130, El saco de enbustres (el comienzo de Aa-Th, 570, La manada de conejos. Variante: Ampudia, $C A$, núm. 57, El pobre y los diablos. Véase también Aa$\mathrm{Th}, 551$, Los bijos buscan un remedio maravilloso para su padre.

Aa-Th, 613, Los dos viajeros. Versión: Camarena, León, núm. 111, El sastre y el albañil. Cf. Aa-Th, 594**, La flauta mágica que bace a todos bailar.

Aa-Th, 621, La piel de piojo. Versiones: Ampudia, CA, núm. 134, El pandero de piel de piojo (combinado con Aa-Th, 513A, Seis van por todo el mundo); núm. 135, La piel de piojo (también combinado con Aa-Th, 513A). Espinosa, CPE, núm. 11, El pandero de piojo (seguida de Boggs, 705*A, Esposa rechazada por ser muda). Espinosa, hijo, núm. 131, Piel de piojo (seguida de Aa-Th, 851, La princesa no acierta el acertijo, y Aa-Th, 570, La manada de conejos). Camarena, León, núm. 112, La gorra de piel de piojo (seguida de Aa-Th, 513A, Seis van por todo el mundo).

Aa-Th, 650A, Juan el fuerte. Versiones: Ampudia, CA, núm. 189, Juan $y$ Medio (seguida de Aa-Th, 560, El anillo mágico, y Aa-Th, 175, El muñeco de brea). Espinosa, CPE, núm. 35, Sansón (seguida de Aa-Th, 175). Camarena, León, núm. 113, El hijo Lacazán (con Aa-Th, 175; núm. 114, El santo de pez (con Aa-Th, 175; núm. 115, El muñeco de pez (con Aa-Th, 175). Véase el comentario de Camarena, León, pp. 429-30. 
Aa-Th, 653, Los cuatro bermanos diestros. Versiones: Ampudia, CA, núm. 12, Los cuatro bermanos. Espinosa, hijo, núm. 132, El ladrón, el sastre, el cazador y el astrónomo. Camarena, León, núm. 116, Los cuatro bermanos bábiles; núm. 117, Los cuatro oficios.

Aa-Th, 676, "Roca, ábrete". Versiones: Espinosa, CPE, núm. 175, Los dos hermanos. Espinosa, hijo, núm. 144, La mala madrasta (en una versión de Aa-Th, 709, Blancanieves).

\section{F. Varios}

Aa-Th, 700, Pulgarcito. Versiones: Espinosa, CPE, núm. 159. María como un ajo. Espinosa, hijo, núm. 133, El piejillo y el mono de pez (termina con Aa-Th, 175, El muñeco de brea); núm. 134, Cabecita de ajo; núm. 135, Almendrita. Camarena, León, núm. 118, Antoñolín; núm. 119, Como un ajo.

Boggs, 705*A, Esposa rechazada por ser muda. Versión: Espinosa, CPE, núm. 11, El pandero de piojo como conclusión de Aa-Th, 621, La piel de piojo).

Aa-Th, 706, La doncella sin brazos. Versiones: Ampudia, CA, núm. 16, La niña sin brazos. Espinosa, CPE, núm. 99, La niña sin brazos; núm. 100, La niña sin brazos; núm. 103, El cisquero y el demonio. Espinosa, hijo, núm. 137, La niña sin brazos, Camarena, León, núm. 120, La fanona de brazos (alterada); núm. 120, A muller sin brazos.

Boggs, 706*B, La mujer perseguida y calumniada. Versión: Espinosa, $C P E$, núm. 104, El diablo maestro.

Aa-Th, 707, Los tres hijos dorados. Versiones: Ampudia, CA, núm. 6, El pájaro que babla, el árbol que canta y el agua amarilla; núm. 19, Los hijos de la mar. Espinosa, hijo, núm. 138, El pájaro sabio; núm. 139, La hija del carbonero; núm. 140, El pájaro que canta el bien y el mal; núm. 141, El árbol del paraíso. Camarena, León, núm. 122, El Palacio de Irás y No Volverás; núm. 123, Las hermanas envidiosas.

Aa-Th, 709, Blancanieves. Versiones: Ampudia, CA, núm. 20, La madrastra envidiosa. Espinosa, hijo, núm. 142, Blancanieves; núm. 143 , Blancaflor. Camarena, León, núm. 124, La ciniestra (con Aa-Th, 676, "Abrete, Ciniestra!" por “Roca, ábrete!").

Aa-Th, 715, Medio Pollo. Versiones: Ampudia, $C A$, núm. 183, Mediogallo. Espinosa, hijo, núm. 146, El pollo que fue a cobrar un real; núm. 147, El pollito.

Boggs, 720*A, El niño que resucita. Versiones: Espinosa, hijo, núm. 148, El niño que resucita; núm. 149, El niño que llegó el último. 


\section{OBSERVACIONES FINALES}

La comparación que se ha hecho de las colecciones de Espinosa, CPE, Espinosa, hijo, y Camarena, León, nos da datos precisos sobre la difusión y conservación en la región estudiada de dos grupos de cuentos tradicionales - los cuentos de animales y los maravillosos. Trataré de resumir los resultados de la investigación haciendo dos listas para cada categoría de cuentos: una, de los tipos muy difundidos, y otra de los cuentos que por su rareza o por otra circunstancia merecen interés especial.

\section{LOS CUENTOS DE ANIMALES}

\section{A. Animales salvajes}

Cuentos muy dinfundidos: Tipo 1, El robo de peces; Tipo 2B, Cesta atada a la cola del lobo; Tipo 15, Robo de la miel fingiendo ser padrino; Tipos 32 y 34, El lobo baja al pozo en un cubo y rescata al zorro en otro, y El lobo se echa al agua creyendo que la luna es queso; Tipo 56A, El zorro amenaza con derribar el árbol; Tipo 60, El zorro y la grulla se invitan mutuamente, Tipo 62, Paz entre los animales. De interés especial: Tipo 37*, El zorro como pastor, Tipo 47C, El lzorrol imitando al lobo, quiere matar un caballo; Tipo 61A, El zorro como confesor (variante); Tipo 67, El zorro dentro del crecido rio pretende estar nadando hacia un pueblo distante.

B. Los animales salvajes y domésticos

Cuentos muy difundidos: Tipo 120, El primero en ver salir el sol; Tipo 122A, El lobo busca su desayuno; Tipo 127.*, El lobo induce a la cabra a que baje de la roca. De interés especial: Tipo 129A*, La oveja lame a su recién nacido.

\section{El hombre y los animales salvajes y domésticos}

Cuentos muy difundidos: Tipo 154, Comida de oso, Tipo 157, Aprendiendo a temer al hombre, Robe, Tipo $157^{*} \mathrm{E}$, El asno recupera los arreos. Tipo 225, [Las bodas en el cielo]. De interés especial: Tipo 153, La castración del (lobol; Tipo 156, La espina sacada de la pata del león (variante); Tipo 159A, [Animales enviados por comida por hombre traidor]; Tipo 165B*, El mayor castigo del lobo: casarlo; Tipo 246, El cazador se dispone a disparar la flecha (variante); Espinosa, hijo, Tipo 260, Los bichos piden dones. 
D. Otros animales y objetos

Cuentos muy difundidos: Tipo 275, La carrera del zorro y el [sapol; Tipo $275^{*} \mathrm{~A}$, La carrera entre la zorra o liebre y el sapo o erizo; Tipo 285B,

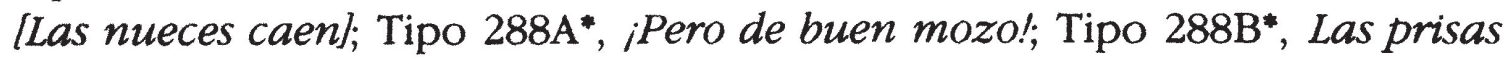
del sapo. De interés especial: Tipo $229 \mathrm{~B}^{*}$, Un águila avisa al pastor de que el lobo está comiendo ovejas; Tipo 275B*, La carrera entre el lobo y la abeja; Boggs, Tipo *290, Un pastor cuida de una culebra.

\section{LOS CUENTOS MARAVILLOSOS}

A. Los adversarios sobrenaturales

Cuentos muy difundidos: Tipo 300, El dragón devastador, Tipo 302, [La vida externada); Tipo 303, [Los gemelos]; Tipo 312C, La novia del ladrón es rescatada; Tipo 313A, La chica ayuda a la fuga del héroe; Tipo 313C, Igual al Tipo anterior + La novia olvidada; Tipo 327B, El muchacho y el gigante, Tipo 328, El muchacho roba el tesoro del gigante; Tipo 330B, El diablo en la mochila; Tipo 332, La muerte de padrino; Tipo 366, La reclamación del muerto. De interés especial: Tipo 307, El [principe] en la mortaja; Tipo 311, (La habitación prohibida); Tipo 327A, La casita de caramelo; Tipo 361, [Un soldado pacta con el diablo].

B. Esposos y otros parientes sobrenaturales

Cuentos muy difundidos: Tipo 408, Las tres naranjas; Tipo 425A, El monstruo como esposo; Tipo 425C, La bella y la bestia; Tipo 425P, Esposa encantada perdida y hallada; Tipo 433B, lEl principe serpiente mata a las novias ariscasl; Tipo 451*, La hermana como misteriosa ama de casa. De interés especial: Tipo 403A, La novia trocada y su hermano; Tipo 409, La muchacha en forma de lobo; Tipo 410, La bella durmiente, Tipo 437, La novia suplantada.

C. Tareas y ayudantes sobrenaturales

Cuentos muy difundidos: Tipo 510A, Cenicienta; Tipo 510B, Traje de oro, plata y estrellas; Tipo 513A, Seis van por todo el mundo. De interés especial: Tipo 501, Las tres ancianas ayudantes. 
D. y E. Objetos y remedios mágicos

Cuentos muy difundidos: Tipo 560, El anillo mágico; Tipo 563, La mesa, el asno y el palo; Tipo 566, Los tres objetos mágicos y las frutas maravillosas; Tipo 570, La manada de conejos; Tipo 621, La piel de piojo; Tipo 650A, Juan el fuerte; Tipo 653, Los cuatro hermanos diestros. De interés especial: Tipo 590, El principe y los brazales; Tipo 613, Los dos viajeros.

\section{F. Otros}

Cuentos muy difundidos: Tipo 700, Pulgarcito; Tipo 706, La doncella sin brazos; Tipo 707, Los tres bijos dorados; Tipo 709, Blancanieves. De interés especial: Boggs, Tipo 705*A, Esposa rechazada por ser muda; Boggs, Tipo $706^{*} \mathrm{~B}$, La mujer perseguida y calumniada; Boggs, Tipo $720^{*} \mathrm{~A}$, El niño que resucita.

Los materiales presentados proporcionan un inventario de los cuentos de animales y los maravillosos recogidos de la tradición oral en Castilla y León durante los últimos setenta años. El hecho de que los cuentos fueran recogidos durante un período limitado da informes precisos sobre la difusión y conservación de los tipos y temas incluidos.

Basados en el catálogo de Aarne- Thompson, el inventario incluye unos 160 tipos, 80 de cuentos de animales y casi el mismo número de cuentos maravillosos. Los cuentos más difundidos son casi los mismos en las tres colecciones. En la más reciente, sin embargo, se observa una tendencia a abreviar la narración. Las partes más afectadas son la introducción (falta en algunos casos) y la conclusión (alterada u olvidada). Interesante también es la relativa abundancia de cuentos muy breves. En algunos casos se tratará de fragmentos de cuentos; en otros serán restos de cuentos no conocidos in toto. En todo caso son testimonio de la vitalidad del cuento oral en la cultura popular.

AURELIO M. ESPINOSA, JR. University of Stanford, California 
La comparación de los cuentos de animales y los maravillosos en tres extensas colecciones de cuentos tradicionales proporciona un inventario de los cuentos de dichos tipos en las regiones de Castilla y León. El hecho de que los cuentos fueron recogidos durante un período limitado da informes precisos sobre la difusión y conservación de los diversos tipos y temas. Basado en el catálogo de Aarne-Thompson, el inventario incluye unos 160 tipos. Los cuentos más difundidos son casi los mismos en las tres colecciones. En la más reciente se observa una tendencia a abreviar la narración y son numerosos los cuentos muy breves. En todo caso, el inventario atestigua la vitalidad del cuento oral en la cultura popular.

The comparison of the animal tales and tales of magic in three large collections of traditional tales provides an inventory of tales of the types mentioned in the areas of Castile and Leon. The fact that the tales were collected during a limited period gives precise information regarding the popularity and preservation of the various themes and types. Based on the catalogue of Aarne-Thompson, the inventory includes some 160 types of tales. The most popular tales are generally the same in the three collections. In the most recent one, a tendency to shorten the tale is apparent, and there is a considerable number of very short tales. In any case, the inventory gives evidence of the vitality of the oral tale in popular culture. 